\title{
Development of gis and database program on website for concerned government office for environmental management under pes and biocarbon concepts
}

\author{
Somkid Phumkokrux ${ }^{1}$, Nutthakarn Phumkokrux ${ }^{2, *}$, Komsan Kiriwongwattana ${ }^{1}$, Supharerk O-In ${ }^{1}$, Akirat Abdulkade ${ }^{1}$, \\ Preeyaporn Muenratch ${ }^{1}$, and Arisa Jirasirichote ${ }^{1}$ \\ ${ }^{1}$ Department of Geography, Faculty of Arts, Silpakorn University, Nakhon Pathom, Thailand \\ ${ }^{2}$ Department of Geography, Faculty of Education, Ramkhamheang University, Bangkok, Thailand
}

\begin{abstract}
This study aims to develop GIS and database program for ecosystem services management, environmental management and policy planning for natural conservation in the representative areas under the Integrated Community-based Forest and Catchment Management through an Ecosystem Services Approach project (CBFCM) by using Payment for Ecosystem Services (PES) and Biological storage of carbon (BioCarbon) concepts. At first, the concerned data were collected by brainstorming of the needs of GIS and database program with staffs from 4 pilot areas in Thailand: Mae Sa watershed area in Chiang Mai, Lam Sae Bai River Basin in Ubon Ratchathani, Tha Chin watershed area in Samut Sakhon and Phangan River Basin in Surat Thani. Then, the situations and variables which affect to natural resources were analysed. Secondly, GIS and database program were designed and developed. However, the program can be divided into 3 sub-programs for different proposes which are; (1) to enhance coordinated and follow-up performance of change of PES and Bio-carbon concept, (2) to increase communication and training for delegate areas to understand about PES and BioCarbon concept and (3) to collect and manage data and information for representative areas.
\end{abstract}

\section{Introduction}

There is an important project which can be applied for environmental management to protect, follow up and conserve all natural resources and cultural in local area called "Integrated Community-based Forest and Catchment Management through an Ecosystem Services Approach (CBFCM)" this project establish by cooperation from Ministry of Natural Resources and Environment of Thailand (MNRE) and United Nations Development Program (UNDP), which is supported by Global Environment Facility (GEF) [1]. This project run under Payment for Ecosystem Services concept (PES) and Biological storage of carbon (BioCarbon) concept to apply environmental policy and manage in local area then, this project also has duty to present successfulness of environmental conservation.

The principle of PES is the relationship between Provider or Seller who prepare, manage and protect any natural resources and ecosystem service (Provisioning Services, Regulating Services, Supporting Services and Cultural Services) [4] in their local for Buyer who want to do some business in this local area. However, Buyer must give the rewards for Provider or Sellers before/after disturb the natural resources in the area and Seller or Provider will use the rewards to repair their natural resources $[1,3]$.
The BioCarbon is a solution to climate change. It is an approach to capture and store carbon dioxide in the plants, trees and soils. Plants typically consume carbon dioxide and convert into plant material via the photosynthesis. This allows carbon dioxide to transfer from atmosphere to the soils. The processes of BioCarbon solution are protecting, replenishing and creating the carbon store in the nature $[5,6]$.

Both PES and BioCarbon mainly focus on two dimensions in Thailand. First dimension is to cooperate with policy, plan and strategy of environmental and natural resources management in the level of local, region and country. Furthermore, the information center for supporting efficient natural resources management is developed. The second is to encourage representative areas to develop and adopt PES and BioCarbon in the local areas. $[7,8]$

This study aims to develop GIS and database program for ecosystem services management, environmental management and policy planning for natural conservation in the representative areas under for concerned government. This program adopts the concept of PES and BioCarbon and has been implemented in 4 pilot areas in Thailand: Mae Sa watershed area in Chiang Mai, Lam Sae Bai River Basin in Ubon Ratchathani, Tha Chin watershed area in Samut Sakhon and Phangan River Basin in Surat Thani. 


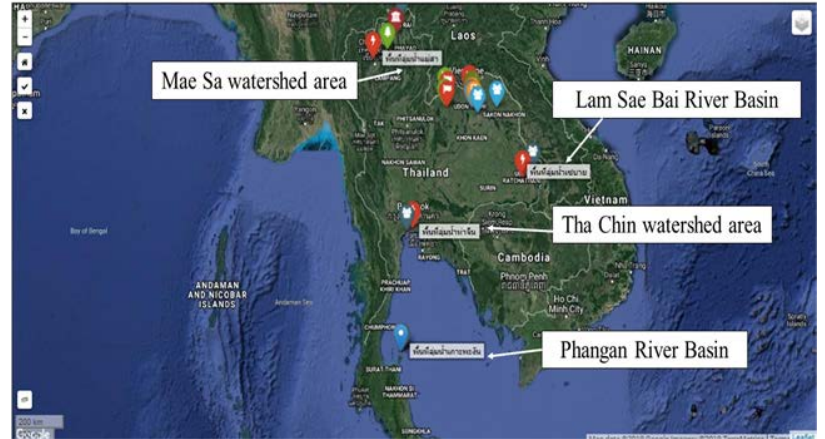

Fig. 1. Study areas with 4 pilot areas (Mae Sa watershed area, Tha Chin watershed area, Lam Sae Bai River Basin and Phangan River Basin).

\section{Procedure and equipment}

\subsection{Study areas}

There are 4 pilot areas around Thailand used in this study which are Mae Sa watershed area (Chiang Mai Province, located in Northern of Thailand), Lam Sae Bai River Basin (Ubon Ratchathani Province, located in Northeastern of Thailand), Tha Chin watershed area (Samut Sakhon Province, located in Central of Thailand) and Phangan River Basin (Surat Thani, located in Southern of Thailand). Moreover, Bureau of Policy and Strategy of MNRE and regional environmental office staffs from these areas cooperate together to help this study. The sample areas map is illustrated in figure 1 .

\subsection{Procedure and Data}

There are 6 steps to operate with this study as presented in figure 2 and the detail are illustrated below.

\subsubsection{Collection of Concerned data.}

1) Ministry of Natural Resources and Environment (MNRE) was supported by Global Environment Facility (GEF) and United Nations Development Program (UNDP) to determine policies and guidelines for creating policy support mechanisms and announce the successfully of Integrated watershed ecosystem management, Forest management, biodiversity and watershed ecosystems under Payment for Ecosystem Services or PES concept.

2) The project was stared in these 4 sample areas. Then, Regional Environment Office and Provincial Offices for Natural Resources and Environment of the representative areas give the knowledge of the project to all concerned people in these areas and brainstorming with all these people to get the detail about the need of GIS and website for supporting the project.

3) MNRE started to hire academic researcher to analyse all variables and situation which were concerned with the project such as Community participation, BioCarbon in these model areas, Community operations related to the ecosystem in the areas etc.

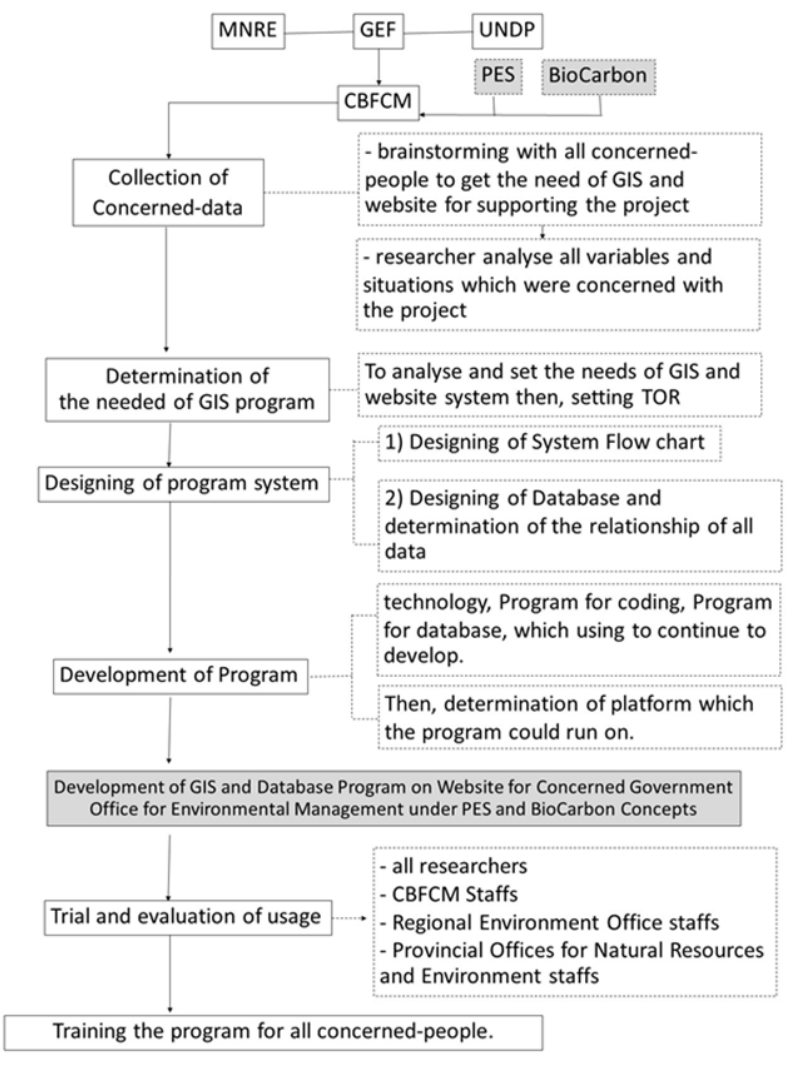

Fig. 2. Procedure of this study.

\subsubsection{Determination of the needed of GIS program.}

All research cooperated with CBFCM staffs, Regional Environment Office and Provincial Offices for Natural Resources and Environment of the sample areas to analyse and set the needs of GIS and website system then, MNRE determine and announce to Term of Reference (TOR)

\subsubsection{Designing of program system.}

All researchers manage and design the GIS and database system which included 1) Designing of System Flow chart and 2) Designing of Database and determination of the relationship of all data

\subsubsection{Development of Program.}

All researchers determine technology, Program for coding, Program for database, which using to continue to develop. Then, determination of platform which the program could run on.

\subsubsection{Trial and evaluation of usage.}

The GIS and Database program were tested by all researchers, CBFCM Staffs, Regional Environment Office staffs and Provincial Offices for Natural Resources and Environment staffs of the sample areas. 


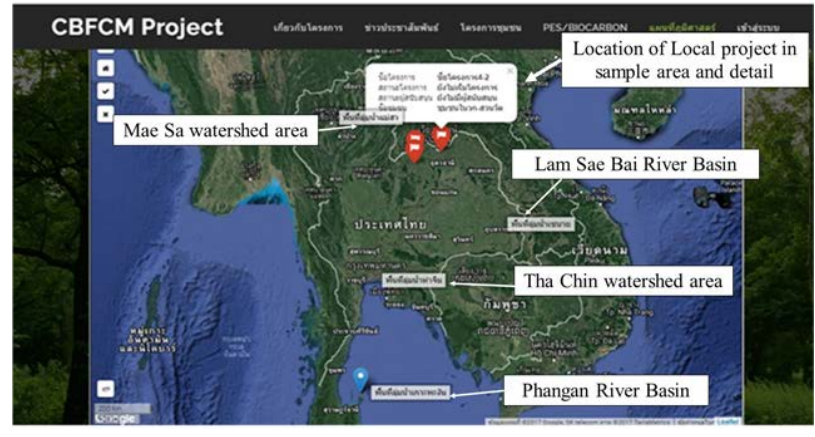

Fig. 3. Location of Local project in sample area and detail.

\section{Results}

Development of GIS and Database Program on Website for Concerned Government Office for Environmental Management under PES and BioCarbon Concepts has the mechanism to apply environmental policy to 4 representative areas for Integrated Community-based Forest and Catchment Management through an Ecosystem Services Approach. Therefore, the program can be separated to 3 sub-programs below to supporting, follow-up, management and giving all helps to representative areas. The programs can be accessed by http://43.228.82.24/cbfcm. The information of These 3 programs can presented below.

1) GIS and Database program for supporting CBFCM office to enhance coordinated and follow-up performance of change of PES concept and Bio-carbon with Regional Environment Office and Provincial Offices for Natural Resources and Environment of the representative areas. The principle of this system is collecting all information about new projects and previous projects which representative areas perform all activities in the projects. The component of this system included (1) Ecosystem type of the projects such as Forest, Catchment, Biodiversity, etc. (2) Project name. (3) Objectives of the project. (4) Detail of the project such as the beginning date, budget, status of the project (available or unavailable or finished), coordinators of the project, Payment for Ecosystem type, attach files, Geographic coordinates of the project (which are shown in the Thailand's map) and etc. as shown in figure 3 and figure 4 Detail of supporter the project which included name of sponsor, sponsor's contact, the beginning date of supporting, Payment for Ecosystem type and project report for sponsor as shown in figure 5. Therefore, Concerned-government officers can find the project location in the map and access to this system to follow up and coordinate the project immediately.

2) GIS and Database program for supporting CBFCM office and Regional Environment Office to increase communication and training for delegate areas to understand about PES and BioCarbon concept. The main concept of this system is when concerned-government officers and representative officers have new knowledge, concerned report and concerned documents, all officer should collect all data in the system then it will connect to GIS and Database program which shown as the map directly.

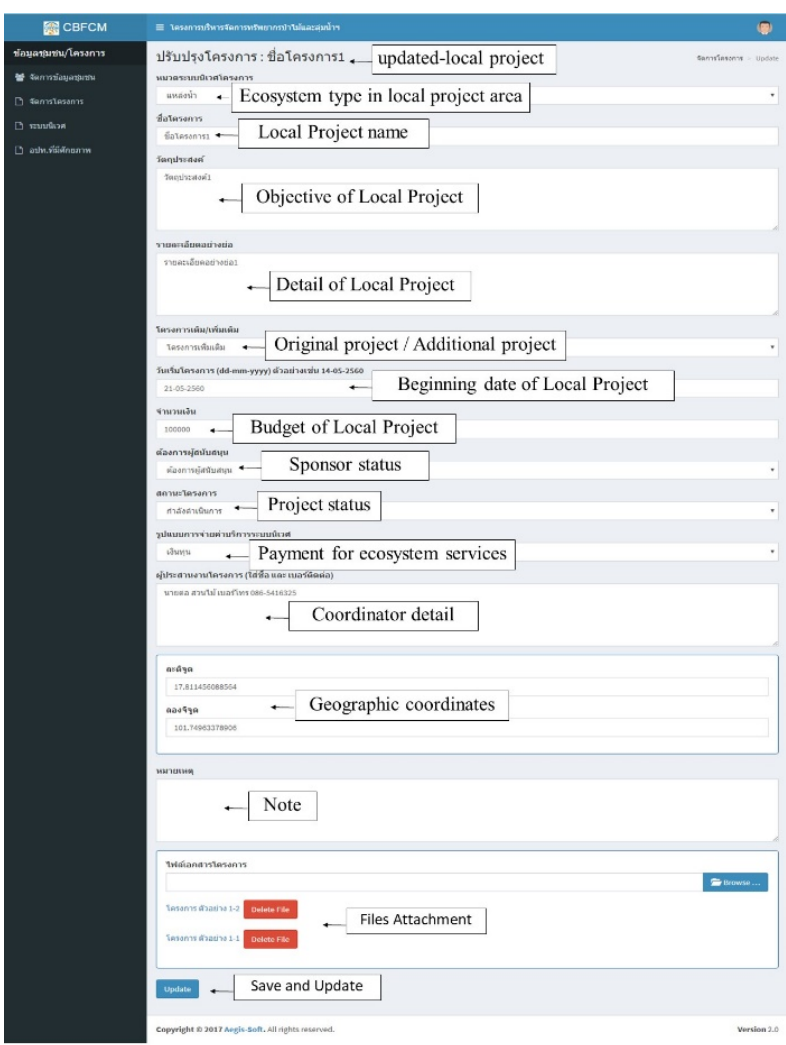

Fig. 4. The window which presented about recording and editing of the local project under PES and Bio-Carbon Concept.

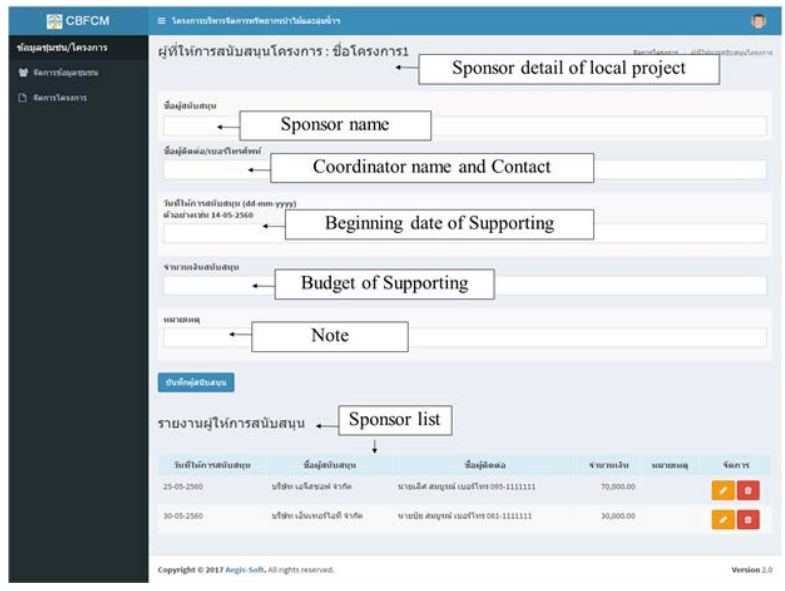

Fig. 5. The window about sponsor details.

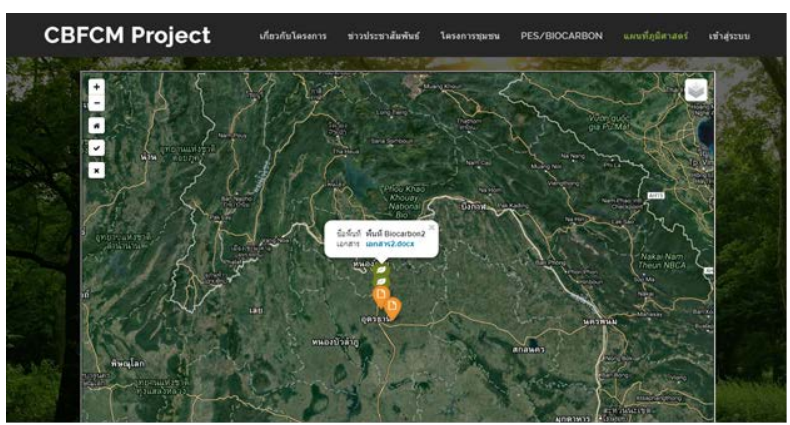

Fig. 6. The location which new knowledges of PES and BioCarbon were recorded in pilot areas. 


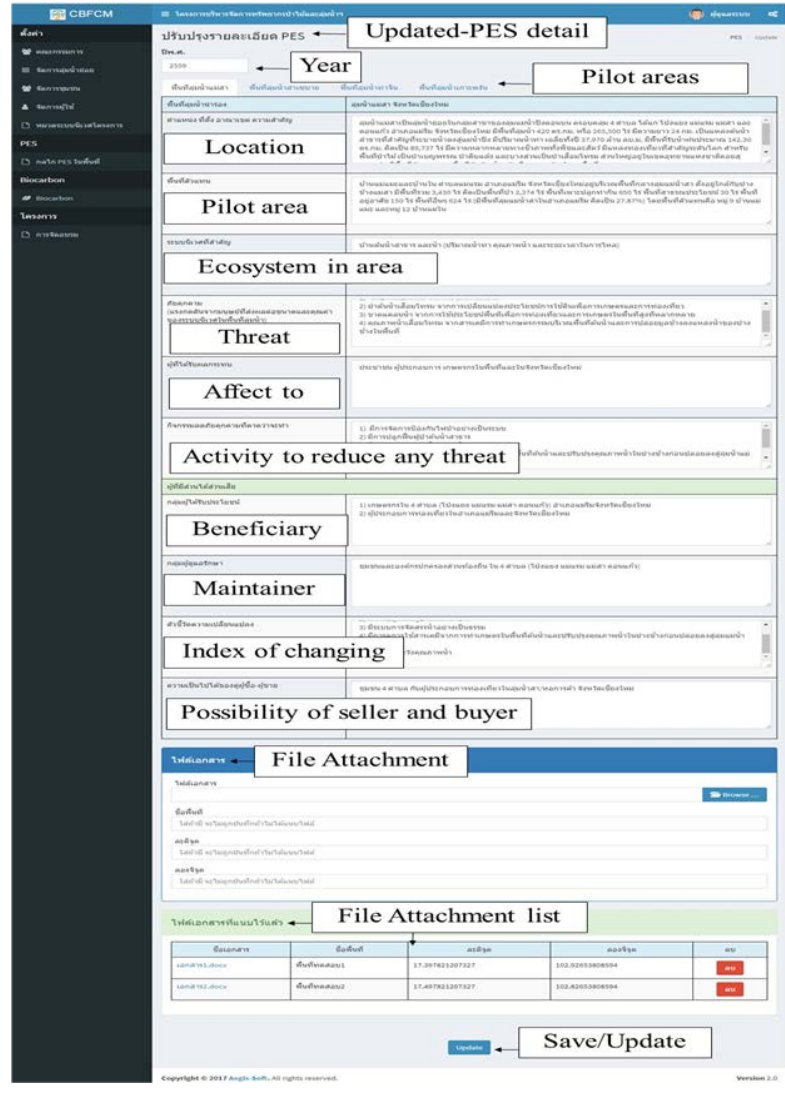

Fig. 7. The window which is presented the recording any new knowledge about PES.

The components of the system include the information about PES and Bio-Carbon in the representative areas, knowledge in document form which concern with PES and Bio-Carbon, Geographic coordinates which concern about PES and Bio-Carbon in representative areas and attachments.

After collecting of all detail which demonstrated above, all officers can enhance their performance to give knowledge and training by using the data in the map and system directly then, apply to community in their areas and others to understand in environmental quality management then, Cooperation of conservation of community resources will active. Therefore, development of the program is beginning when concerned-government officers and researchers get the new knowledge or any detail from the map as presented in figure 6. The information about recording any new knowledge about PES and Bio-Carbon are shown in figure 7 and figure 8 .

3) GIS and Database program for supporting these representative areas to collect and manage their data and information. The component includes list of committees, Geographic coordinates of the project, Implementation guidelines and follow-up and attachment. All information would connect to GIS and database system on the website directly as shown in figure 9 and figure 10 .

\section{Conclusions and Suggestions}

PES and BioCarbon are essential concept which can be used for environmental management and environmental conservation in these 4 representative areas. And these concepts bring all researchers to design the GIS and Database program called "Development of GIS and Database Program on Website for Concerned Government Office for Environmental Management under PES and Bio-Carbon Concepts" which included 3 sub-programs as shown above. Moreover, the program can help concerned-government, researchers and local people to understand PES and Bio-Carbon concept and work together to run any environmental management and protection project easily for these local areas. However, these programs still have a big disadvantage point. The users have to connect to the system by http://43.228.82.24/cbfcm, there is no any domain name currently. Moreover, this would be inconvenience and this would be easily to forget how to access for all users thus, this problem is essential for all researchers to develop the domain name and enhance system performance in the future.

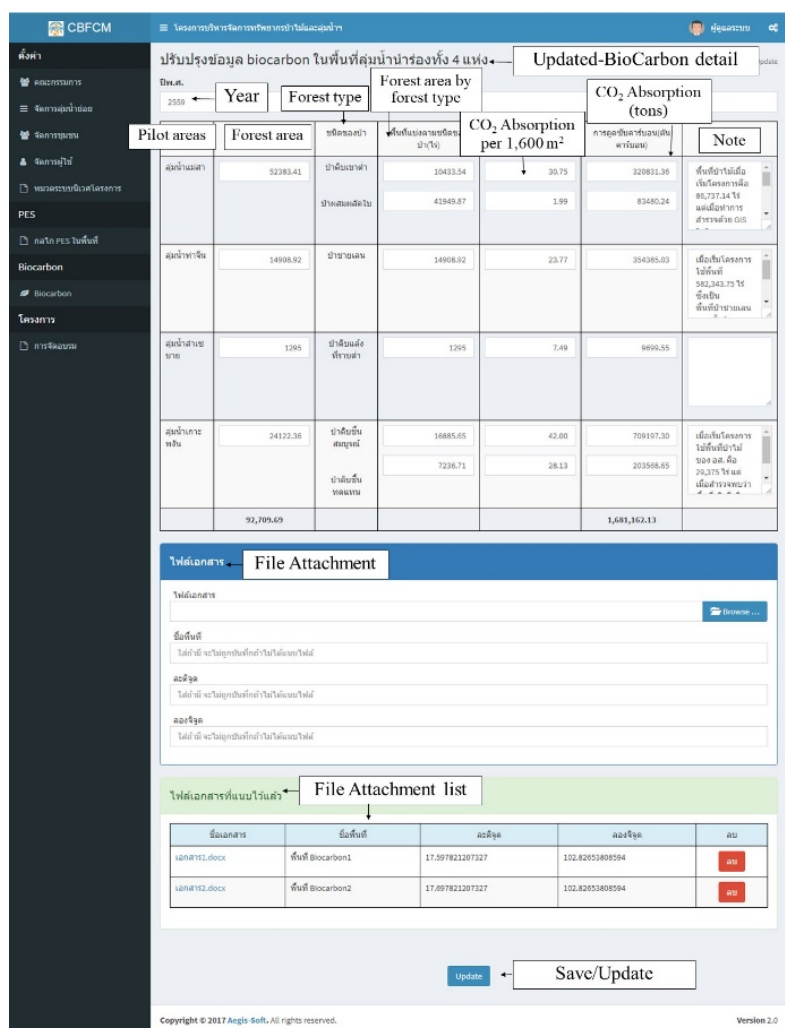

Fig. 8. the window which is presented the recording any new knowledge about Bio-Carbon.

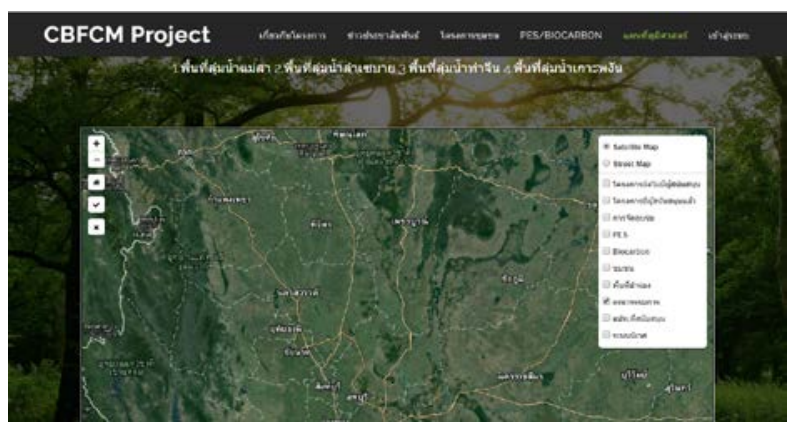

Fig. 9. The location of project's committee in sample areas. 


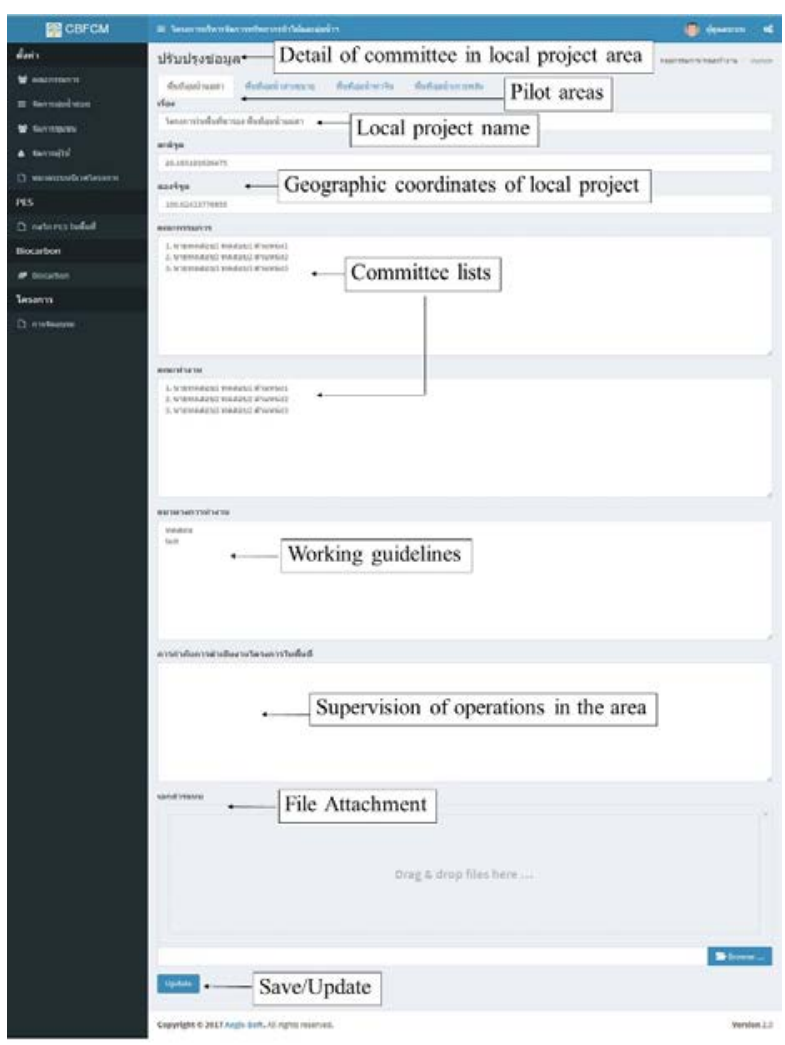

Fig. 10. the window which is presented about the detail of committee in local project area.

Authors would like to say thank you to Ministry of Natural Resources and Environment of Thailand (MNRE) for financial support and four representative areas which are; Mae Sa watershed area, Lam Sae Bai River Basin, Tha Chin watershed area and Phangan River Basin for supporting all data which are essential in this study.

\section{References}

1. Payment for Ecosystem Service: PES Agriculture, Natural Resource and Environment Planning Office,
Office of the National Economic and Social Development Board, Bangkok, Thailand (2011)

2. Ecosystems and Human Well-being: Synthesis, Millennium Ecosystem Assessment, Washington, DC (2005)

3. Uganda's first Payment for Environmental Services Fund launched, United Nations Development Programme in Uganda, Kampala, Uganda (2015), Available from: http://www.ug.undp.org/content/uganda/en/home/pre sscenter/articles/2015/03/27/uganda-s-first-paymentfor-environmental-services-fund-launched-.html.

4. S. Wunder, Payments for Environmental Services: Some nuts and bolts, CIFOR Occasional Paper No.42 (2005)

5. Climate Solutions [internet], "About Biocarbon" Available from: https://www.climatesolutions.org/programs/nbi/about -biocarbon

6. United Nations Development Program [Internet], "Project: Integrated Community-Based Forest and Catchment Management through an Ecosystem approach (cbfcm)" (2015) [cited 2019 Jun 1] Available from: https://www.undp.org/content/dam/thailand/docs/oth ers/Community $\% 20$ based $\% 20$ forest $\% 20$ and $\% 20$ catc hment $\% 20$ management $\% 20$ through $\% 20$ an $\% 20$ ecosy stem $\% 20$ approach $\% 20$ project $\% 20$ factsheet $\% 20$ Final .pdf

7. E. Fripp and B. Shantiko, Payment for Ecosystem Services (PES): Assessment of PES Potential in Kapuas Hulu, Center for International Forestry Research (2014)

8. Food and Agriculture Organization of the United, The State of Food and Agriculture 2007, Electronic Publishing Policy and Support Branch Communication Division (2007) 